fulfil this role are none other than those discovered by Fuster and Niki. If their persistent activity in the absence of a sensory cue is indeed the step of calculating a single decision variable based on information from several sources, then neurophysiologists have actually watched neurons making up the monkey's mind. What determines the moment of decision is not yet known, but just as 'decide' once meant to cut off, or bring to an end, so these neurons do indeed stop their activity when the decision is made.

There is a strong argument that we have made such great progress in understanding the neural basis of cognition only because neurons, and the networks that they form, compute in an analogue style. We can get an idea of the underlying computations by measuring the activity of single neurons, or the strength of the functional magnetic resonance imaging signal. It seems fantastic, but Fuster's progress report dares us to believe that the patterns woven by Sherrington's "enchanted loom", the cerebral cortex, are now well on the way to being understood.

Kevan Martin is at the Institute of

Neuroinformatics, University of Zurich/ETH, Winterthurerstrasse 190, 8057 Zurich, Switzerland.

\section{Suffocated or shot?}

\section{When Life Nearly Died: The Greatest Mass Extinction of \\ All Time}

by Michael Benton

Thames and Hudson: 2003. 336pp.

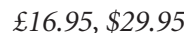

\section{Peter J. Bowler}

Whatever hit the Earth at the end of the Permian period certainly struck hard, killing $90 \%$ of living species. Compared with this, the extinction at the end of the Cretaceous period was comparatively minor, with only a $50 \%$ death rate. Yet the latter event is much better known, because among that 50\% were the last of the dinosaurs. Partly for this reason, Michael Benton uses the event at the end of the Cretaceous as an introduction to his account of the Permian extinction - he wants us to realize how limited it was in comparison with what he intends to describe.

But there is a deeper reason for linking the two episodes: Benton wants to show us how the catastrophist perspective has re-emerged in modern geology and palaeontology. $\mathrm{He}$ argues that the theory of catastrophic mass extinctions was widely accepted in the early nineteenth century, but was then driven underground by the gradualist perspective of Charles Lyell's uniformitarian geology and Darwin's theory of evolution. Only in the 1970s was catastrophism revived, through the claim that the dinosaurs were wiped out when an asteroid hit the Earth. Benton shows

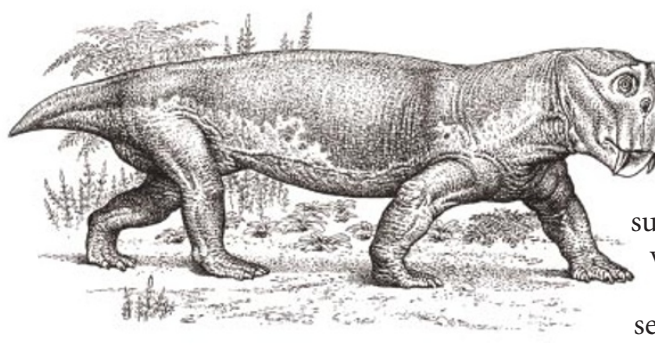

But such ideas went out of fashion in the mid-nineteenth century, and later catastrophists, including Murchison, favoured explanations based on the supposedly more intense geological activity in the young Earth. The asteroidimpact theory of dinosaur extinctions seems to parallel some of the earliest

Exit stage right - even though Lystrosaurus survived the extinction at the end of the Permian.

us how in the 1990s the evidence began to emerge that the species replacements marking the Permian-Triassic transition were also sudden, and hence were probably caused by some environmental trauma. He is describing both a geologically sudden event and a rapid transformation in our ideas about the Earth's past.

As a result, the book is partly historical in nature. It describes how the British geologist R. I. Murchison (himself a catastrophist) defined the Permian rocks of Russia in about 1840, and how Lyell and Darwin challenged the idea of mass extinctions by arguing that apparently sudden transitions in the fossil record were the result of gaps in the evidence, which created illusory jumps between one system of rocks and the next.

The triumph of darwinism ensured that catastrophist explanations were marginalized until they were revived by the asteroidimpact theory for the end of the Cretaceous. Even then, many palaeontologists resisted, arguing that the dinosaurs were declining anyway, so the impact only finished a job that had already been started by gradual environmental changes. At the time, knowledge of the Permian-Triassic transition was so limited that gradualism still seemed plausible here, too. Benton provides a graphic account of how more recent evidence has piled up, including his own experiences fossil hunting in Russia, making a catastrophic explanation inescapable.

There is one important twist in the story, however: Benton finds little support for the possibility that the Permian extinction was caused by an extraterrestrial agent. Wild theories about periodic bombardments by asteroids have not stood the test of time: the Permian event was probably triggered by massive volcanism, which injected poisonous gases into the atmosphere, both directly and by triggering the release of methane from deep-sea hydrates. Some geologists think that volcanism also played a role at the end of the Cretaceous. Significantly, Benton concludes by considering the implications of the latest, man-made mass extinction, asking what light the earlier events can throw on the potential for survival of modern species.

The historical aspect of Benton's book raises some intriguing questions. Many early catastrophists postulated the involvement of extraterrestrial agents - a comet was sometimes invoked as the cause of Noah's flood. speculations, but Benton has redressed the balance by favouring internal causes.

My one criticism of his account is that he accepts too readily the assumption that Lyell and Darwin marginalized all support for discontinuity in the Earth's history. There were few outright catastrophists left by around 1900, but many still believed that the history of life had been punctuated by environmental transitions far more rapid than anything observed in the recent past.

The real triumph of gradualism came with the modern darwinian synthesis of the mid-twentieth century, and even then it was confined to the English-speaking world. Benton notes that British and US palaeontologists of the 1950s ignored the catastrophism of Otto Schindewolf. But we need to recognize that German palaeontologists such as Schindewolf were continuing a long-standing tradition that had proved far more robust than our modern, Darwincentred histories acknowledge. The fact that modern catastrophists do not see a link back to that tradition tells us about the effectiveness of the neo-lyellian interlude of the mid-twentieth century.

Peter J. Bowler is in the Department of Social Anthropology, Queen's University Belfast, Belfast BT7 1NN, UK

\section{Hooke, life and thinker}

London's Leonardo: The Life and Work of Robert Hooke

by Jim Bennett, Michael Cooper,

Michael Hunter \& Lisa Jardine

Oxford University Press: 2003. 240 pp.

$£ 20, \$ 35$

\section{David R. Oldroyd}

Some devotees of Robert Hooke have regarded him as Britain's greatest scientific genius of the seventeenth century, the range of his interests and achievements being hard to conceive. He is a fruitful subject for historical enquiry as he left behind him a large archival trail, and, with his polymathic interests, he has attracted much attention. A good general overview, Robert Hooke by Margaret 'Espinasse (Heinemann), was published in 1956. Since then, studies of Hooke have expanded greatly to the point where we have a detailed knowledge of the man, although not all within the pages of a 
single volume. London's Leonardo contains four highly competent and complementary essays, which go a long way towards providing a definitive account of Hooke, while leaving open the road (or preparing the way) for a full intellectual biography.

Hooke was wealthy at his death, much of his money having come from his work helping to resurvey London after the Great Fire of 1666. In his essay, Michael Cooper describes this work pleasantly and informatively. That Hooke should have embarked on it when he was already fully occupied with his scientific work for the Royal Society is remarkable and bespeaks his devotion to London and its inhabitants. There were many problems. With street widening, residents had to be compensated fairly for the land they were to lose. Buildings had different owners on different floors, and some structures had 'interleaved' with their neighbours. An accurate survey was needed, and it relied on instruments, some devised by Hooke, that were an integral part of the 'scientific revolution'. Hooke's contributions to the survey were substantial.

Jim Bennett's fine paper, which is profusely illustrated, deals with Hooke's instruments and inventions more generally, revealing their extraordinary range and ingenuity: time-pieces, air pumps, telescopes and microscopes, meteorological and oceanographic instruments, the universal joint and many other items. Hooke believed in the use of instruments to enhance the senses, as can be seen from his controversy with the Polish astronomer Johannes Hevelius, who still advocated naked-eye instruments for astronomy. Hooke was clearly on the winning side. Everyone knew that optical instruments had imperfections, and Hooke applied himself to the endless task of their improvement.

Michael Hunter writes about Hooke's philosophy of nature and his ideas on scientific method. Regarding the latter, Hooke was not a baconian inductivist (nor, indeed, was Bacon), but rather a hypothetico-deductivist. Although Hooke made some use of baconian tables of 'presence', 'absence' and 'degrees', he gave a clear example of the formulation and

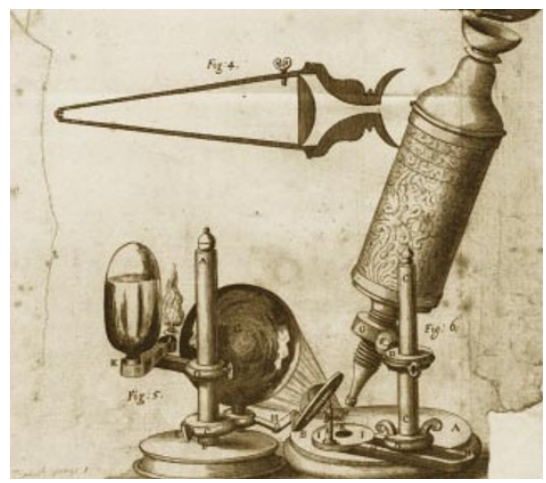

Instrumental to his success: Hooke relied on optical devices such as this compound microscope.

\section{Art}

\section{Science in site}

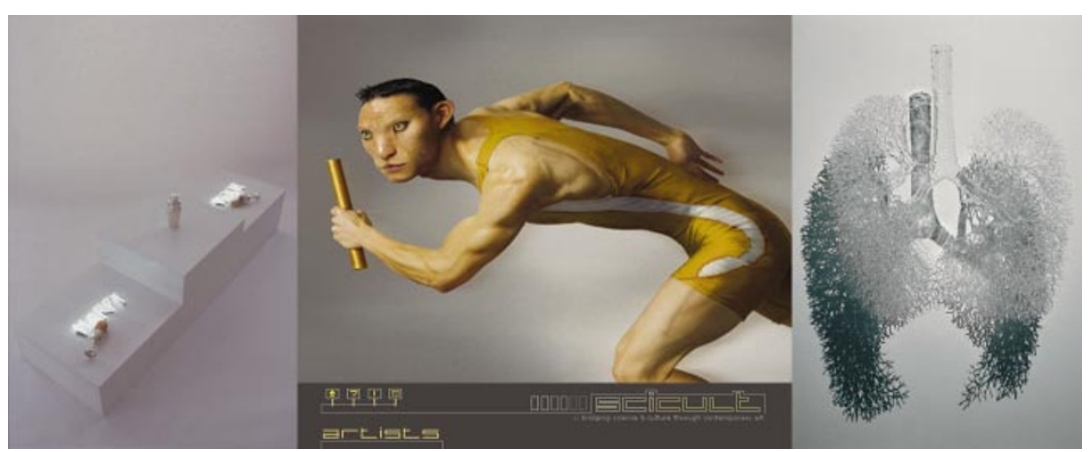

Taking issue: Happy Hour by Fernando Arias (left) examines AIDS treatments; Daniel Lee focused on evolution for Cheetaman (middle); and Annie Cattrell's Capacity was inspired by the breath of life.

The website scicult.com is a science-related contemporary art gallery - and an act of love. The small group of 'sci-art' specialists who launched it earlier this year are idealists, committed to promoting a quality marriage of art and science.

The group has already signed up 20 significant artists, including Annie Cattrell and Fernando Arias, some of whose whose work is shown here. The art is exhibited in the online gallery, and some pieces will eventually be available for sale.

But scicult.com is more than a gallery. It publishes an expanding range of intelligent features about contemporary sci-art, and has

testing of hypotheses in science. He proposed the idea of pole-wandering to account for cyclical interchanges of the levels of land and sea (to explain the presence of inland fossils). Such movements in the position of the geographic poles, if they occurred, would, over time, produce changes in the direction of the meridian at any given locality. Hooke then suggested astronomical methods for the accurate determination of the meridian, which should be measured over a period of years to look for changes. A first attempt at determination failed because of poor weather and the idea was not pursued, being pushed aside by Hooke's manifold other activities, but the hypothetico-deductive method was clearly enunciated.

This example, in a way, renders superfluous historians' worries about what Hooke meant by what he mysteriously called 'philosophical algebra', presumably some kind of 'routinizable' procedure for conducting science. Of course, knowing about the 'form' of scientific method tells us little about how Hooke's creative process worked. Hunter, unlike another Hooke aficionado, Steve Shapin, eschews discussion of the significance of Hooke's social status for his scientific practice. Rather, Hunter gives an excellent exposition of Hooke's Micrographia, which links back to the discussion of instruments, and further illustrates his procedures. longer-term plans to develop an 'introduction service' for scientists and artists who seek collaborating partnerships. It is also in the process of acquiring a permanent, real-world gallery in which it can exhibit more experimental works.

The website is attractive and functional. Artworks are well displayed against a dark-grey background and can be enlarged with a click of the mouse. The features are timely and wellwritten, but suffer the plague of many web pages designed primarily for visual impact: the text, reversed out white on dark grey, is a strain to read on the screen.

Alison Abbott

www.scicult.com

Lisa Jardine's paper is less precisely focused than the other three. She explicates details of Hooke's relations with Robert Boyle, and writes about Hooke's work on pressures, the magnitude of subterranean gravitational attraction and geology. But she is chiefly interested in his health and his self-medication (recorded in his diary), which eventually more or less killed him. Hooke left no will, and his family fell on his fortune after he died. They were not interested in preserving his name, so for many years he was a rather forgotten figure (Jardine suggests). But his time has come: the comprehensive bibliography of London's Leonardo shows just how many works have been written about him since'Espinasse's biography.

This prompts a thought. People's interests can often be judged by their libraries. Hooke's printed library sale catalogue survived, and some years ago I attempted an approximate classification of his books. The number of literary items (languages, grammar, philology, poetry, plays, epigrams and biographical works) easily exceeded the number in any of the categories of mathematics, astronomy, logic, physics, architecture, machines and so on. Is there perhaps another Hooke to be explored: the man of letters?

David R. Oldroyd is in the School of History and

Philosophy, University of New South Wales,

Sydney 2052, Australia. 